\title{
Implementasi Metode ANP-PROMETHEE Untuk Pemilihan Supplier (Studi Kasus PT. Lamongan Marine Industry)
}

\author{
Ma'had Wicaksono ${ }^{\mathrm{a}^{*}}$, Bayu Surarso ${ }^{\mathrm{b}}$, Farikhin $^{\mathrm{b}}$ \\ ${ }^{a}$ Magister Sistem Informasi, Universitas Diponegoro \\ ${ }^{\mathrm{b}}$ Departemen Matematika, Universitas Diponegoro \\ Naskah Diterima : 27 September 2019; Diterima Publikasi : 14 Februari 2020 \\ DOI: 10.21456/volloiss1pp36-45
}

\begin{abstract}
The selection of suppliers is essential to minimize the cost of procuring raw materials for production. This research is important to do in order to increase company profits and ensure the smooth production process. This study aims to select suppliers of shipbuilding raw materials of PT. LMI based on the best ranking order using the ANP-PROMETHEE method implemented in a decision support system. The variables used are 16 sub criteria and 6 alternatives. The ANP-PROMETHEE method is used because of its advantages in handling multi-criteria assessment based on subjective assumptions from decision makers. Stages of the study began with the ANP method to get the importance of weight then proceed to the calculation with the PROMETHEE method to get an alternative ranking. The results of this study is an application as a Decision Support System (DSS) that can help make supplier selection based on predetermined criteria. From the results of the study it was concluded that the ANP-PROMETHEE method can be implemented and is the right solution for supplier selection, ANP handles the problem of multiple objective decision making so that objectivity is maintained, while PROMETHEE handles the multi attribute decision making problem. Other conclusions are obtained that the PROMETHEE calculation has a more significant influence in determining the final outcome of an alternative ranking than the ANP. An input of ANP value is needed with a long number interval so that the results of the calculation of the Consistency Ratio (CR) approach the CR threshold (0.1) so that the ANP has a significant influence in determining the final outcome of an alternative ranking. The CR number that was tested was 0.0629 and proved unable to change the alternative ranking final results, when the CR number that was tested was 0.0993 , it was proven to be able to change the alternative ranking final results.
\end{abstract}

Keywords: ANP; PROMETHEE; Decision Support System; Selection of Suppliers

\begin{abstract}
Abstrak
Pemilihan supplier menjadi hal yang sangat penting untuk meminimalisasi biaya pengadaan bahan baku produksi. Penelitian ini penting untuk dilakukan demi meningkatkan keuntungan perusahaan dan memastikan kelancaran proses produksi. Penelitian ini bertujuan untuk melakukan pemilihan supplier bahan baku pembuatan kapal pada PT. LMI berdasarkan urutan ranking terbaik menggunakan metode ANP-PROMETHEE yang diimplementasikan dalam sebuah sistem pendukung keputusan. Variabel yang digunakan adalah 16 sub kriteria dan 6 alternatif. Metode ANP-PROMETHEE digunakan karena kelebihannya dalam menangani penilaian multi kriteria atas dasar anggapan subjektif dari pengambil keputusan. Tahapan penelitian dimulai dengan metode ANP untuk mendapatkan bobot kepentingan kemudian dilanjutkan ke perhitungan dengan metode PROMETHEE untuk mendapatkan ranking alternatif. Hasil dari penelitian ini adalah sebuah aplikasi sebagai Sistem Pendukung Keputusan (SPK) yang dapat membantu dalam pemilihan supplier berdasarakan kriteria yang ditentukan. Dari hasil penelitian didapatkan kesimpulan bahwa metode ANP-PROMETHEE dapat diimplementasikan dan merupakan solusi yang tepat untuk pemilihan supplier, ANP menangani permasalahan multiple objective decision making agar objektivitas terjaga, sedangkan PROMETHEE menangani permasalahan multi attribute decision making. Didapatkan kesimpulan lainnya bahwa perhitungan PROMETHEE mempunyai pengaruh yang lebih signifikan dalam menentukan hasil akhir peringkat alternatif dibandingkan dengan ANP. Dibutuhkan masukan nilai ANP dengan interval angka yang jauh sehingga hasil perhitungan Consistency Rasio (CR) mendekati angka threshold CR $(0,1)$ agar ANP mempunyai pengaruh yang signifikan dalam menentukan hasil akhir peringkat alternatif. Angka CR yang diujicobakan adalah pada angka 0,0629 dan terbukti tidak mampu mengubah hasil akhir ranking alternatif, ketika angka CR yang diujicobakan adalah pada angka 0,0993, terbukti mampu mengubah hasil akhir ranking alternatif.
\end{abstract}

Keywords: ANP; PROMETHEE; Sistem Pendukung Keputusan; Pemilihan Supplier

*) Penulis korespondensi : mahadwicaksono@gmail.com 


\section{Pendahuluan}

Penerapan Sistem Pendukung Keputusan (SPK) semakin memiliki peranan penting dalam sebuah keputusan bisnis. Sistem Pendukung Keputusan (SPK) merupakan sistem yang mampu memberikan kemampuan pemecahan masalah maupun kemampuan pengkomunikasian untuk masalah dengan kondisi semi terstruktur dan tak terstruktur. Tahapan SPK dimulai dengan pendefinisian masalah, lalu dilanjutkan dengan pengumpulan data atau elemen informasi yang relevan, langkah berikutnya adalah pengolahan data menjadi informasi, dan yang terakhir adalah menentukan alternatif-alternatif solusi. Tujuan SPK adalah membantu menyelesaikan masalah semi terstruktur, membantu pengambil keputusan dalam menentukan suatu keputusan, serta meningkatkan efektivitas pengambilan keputusan.

Penelitian ini bertujuan menghasilkan model SPK yang mampu membantu pengambil keputusan dalam menentukan supplier terbaik dalam aspek Multi Criteria Decision Making (MCDM). Permasalahan yang akan diselesaikan dalam penelitian ini adalah menentukan supplier terbaik bagi perusahaan yang difokuskan pada supplier bahan baku berupa plat feed 6 dengan ketebalan 14 milimeter. Supplier bahan baku ini menjadi fokus obyek penelitian karena bahan baku tersebut adalah bahan baku utama yang paling banyak digunakan dalam pembuatan kapal besi pada PT. LMI. Proses penyelesaian masalah dalam aspek Multi Criteria Decision Making (MCDM) tidak bisa dilepaskan dari proses evaluasi agar tujuan MCDM tercapai dengan baik. Evaluasi terhadap supplier memegang peranan penting sebagai upaya strategis suatu perusahaan demi meningkatkan keuntungan. Langkah tersebut terpengaruh besar terhadap daya saing perusahaan dalam aspek penghematan biaya pengadaan bahan baku. Jumlah penelitian untuk mengatasi masalah pemborosan dalam hal pembelian bahan baku dengan berbagai metode telah mengalami peningkatan (Bruno et al., 2012).

Evaluasi dalam pemilihan supplier merupakan cara penting dalam menjaga hubungan antara perusahaan dengan supplier (Dobos dan Vörösmarty, 2014). Penilaian supplier dilakukan dengan mempertimbangkan dimensi ekonomi, lingkungan, dan sosial agar dapat menetapkan supplier terbaik dan memastikan bahwa rantai pasok akan berjalan dengan maksimal dan berkelanjutan. Hasil dari evaluasi dan penilaian tersebut akan menjadi dasar kebijakan dalam manajemen operasi perusahaan (Govindan et al., 2015). Untuk menentukan pemasok yang dapat dikatakan layak dan sesuai dengan kriteria perusahaan, tentunya dibutuhkan suatu sistem pendukung keputusan.

Dalam pemrosesannya, SPK dapat menggunakan bantuan dari metode atau sistem tertentu seperti
Artificial Intelligence, Fuzzy Logic, ANP (Analytical Network Process), PROMETHEE (Preference Ranking Organization Method for Enrichment Evaluation), dan lain sebagainya. Berdasarakan studi kasus di lapangan, penelitian ini membutuhkan metode yang mampu menangani dua unsur utama dalam MCDM yaitu MODM (Multi Objective Decision Making) dan MADM (Multi Attribute Decision Making). MODM merupakan unsur dari MCDM yang fungsi utamanya adalah merancang alternatif terbaik, sedangkan MADM merupakan unsur dari MCDM yang fungsi utamanya adalah melakukan seleksi alternatif terbaik.

Dalam penelitian ini kombinasi metode ANPPROMETHEE dipilih untuk digunakan sebagai metode dalam hal pemecahan masalah tersebut. Alasan utamanya adalah karena kombinasi metode tersebut memiliki solusi yang memadai pada permasalahan MODM (aspek konsep) dan MADM (aspek seleksi) serta didasarkan pada situasi saat pengambilan keputusan terkait dengan studi kasus yang terjadi di lapangan.

Secara spesifik, kombinasi ANP-PROMETHEE dimulai dari tahap penentuan masalah. Lalu dilanjutkan penentuan kriteria dan bobot kriteria, di sinilah metode ANP diandalkan untuk mengevaluasi faktor-faktor yang ada, baik yang berwujud maupun yang tidak berwujud. Selanjutnya digunakan metode PROMETHEE untuk menentukan peringkat alternatif, mulai dari yang terbaik hingga yang terburuk (Kilic et al., 2015).

Pada penelitian sebelumnya metode ANP digunakan untuk pendukung keputusan pada strategi manajemen stok dan pemesanan dan perencanaan produksi serta kontrol aktifitas pada perusahaan manufaktur (Rafiei dan Rabbani, 2004). Metode ANP dapat membantu pengambil keputusan dalam memilih model strategi yang optimal dengan melihat beberapa faktor pendukung untuk mengevaluasi strategi daur ulang yang optimal pada industri energi surya (Shiue dan Lin, 2012). Metode ANP juga digunakan pada pendukung keputusan untuk menentukan teknologi yang tepat pada pengolahan sampah di perkotaan (Lami dan Abastante, 2014).

Pada penelitian sebelumnya, metode PROMETHEE digunakan sebagai solusi pemecahan permasalahan dalam pemilihan atau penentuan suatu keputusan manajemen bisnis berdasarkan konsep berkelanjutan (Vinodh dan Girubha, 2012). Metode PROMETHEE berfungsi dengan baik saat digunakan memprediksi kebangkrutan untuk lembaga berdasarkan kerukunan dan kejanggalan hubungan antar anggota organisasi (Hu dan Chen, 2011).

Metode ANP-PROMETHEE dapat digunakan dalam pemecahan masalah pemilihan bahan (material) terbaik untuk produk yang melibatkan sejumlah besar atribut, baik yang termasuk kualitatif maupun kuantitatif. Di antara atribut tersebut 
terdapat ketergantungan dari berbagai sisi dalam sebuah permasalahan MADM (Multi Attribute Decision Making) di lingkungan yang berbeda-beda. Metode ANP-PROMETHEE mampu memberikan hasil penyaringan yang tepat dan memperbaiki solusi terakhir secara baik dan optimal. Pertimbangan pemilihan bahan tidak hanya berdasarkan atribut secara umum seperti kegunaan, kemampuan, dan biaya. Akan tetapi juga mempertimbangkan dampak material pada lingkungan dan aspek budaya (Peng dan Xiao, 2013).

Dalam pembobotan kriteria, metode ANP memiliki keunggulan dalam menangani struktur kerja yang kompleks dalam hal penentuan dan pembobotan kriteria alternatif (Kilic et al., 2015). Sedangkan dalam ranking alternatif, metode PROMETHEE merupakan metode yang sangat dikenal dengan baik dan banyak digunakan dalam outranking untuk perbandingan berpasangan alternatif di setiap kriteria terpisah (Vinodh dan Girubha, 2012).

Berdasarkan latar belakang tersebut maka digunakan metode kombinasi Analytical Network Process (ANP) dan Preference Ranking Organization Method for Enrichment Evaluation (PROMETHEE) untuk pemilihan supplier plat kapal.

\section{Kerangka Teori}

\subsection{Analytical Network Process (ANP)}

Analytic Network Process merupakan teori umum pengukuruan relatif yang digunakan untuk menurunkan rasio prioritas komposit dari skala rasio individu yang mencerminkan pengukuran relatif dari pengaruh elemen-elemen yang saling berinteraksi berkenaan dengan criteria control (Saaty, 1996).

Dalam metode ANP terdapat 2 (dua) kontrol, kontrol pertama adalah kontrol hierarki yang menunjukkan keterkaitan kriteria dan sub kriterianya, sedangkan kontrol lainnya adalah kontrol keterkaitan yang menunjukkan adanya saling keterkaitan antar kriteria atau cluster.

ANP adalah teori matematika yang memungkinkan seseorang untuk memperlakukan dependence dan feedback secara sistematis yang dapat menangkap faktor-faktor tangible dan intangible. ANP merupakan pendekatan baru dalam proses pengambilan keputusan yang memberikan kerangka kerja umum dalam memperlakukan keputusan-keputusan tanpa membuat asumsi-asumsi tentang independensi elemen-elemen pada level yang lebih tinggi dari elemen-elemen pada level yang lebih rendah dan tentang independensi elemenelemen dalam suatu level. Terlebih ANP menggunakan jaringan tanpa harus menetapkan level seperti pada hierarki yang digunakan dalam Analytic Hierarchy Process (AHP). Konsep utama dalam ANP adalah influence (pengaruh), sementara konsep utama dalam AHP adalah preferensi (Saaty, 1999).
Perbandingan berpasangan dilakukan untuk membandingkan kriteria-kriteria dengan cara berpasangan pada setiap alternatif. Nilai eigen merupakan nilai karakteristik suatu matriks. Secara sederhana, nilai eigen merupakan nilai yang merepresentasikan suatu matriks dalam perkalian suatu vektor.

Eigen Vector merupakan bobot prioritas suatu matriks yang kemudian digunakan dalam penyusunan supermatriks. Matriks yang dihasilkan dari perbandingan yang dilakukan secara acak merupakan suatu matriks yang mutlak tidak konsisten. Maka dari matriks acak tersebut didapatkan juga nilai Consistency Index (CI) dan Random Index (RI). Dengan membandingkan CI dan RI, maka didapatkan patokan untuk menentukan tingkat konsistensi suatu matriks yang disebut dengan Consistency Ratio (CR).

Tahapan umum pengambilan keputusan dengan menggunakan Analytical Network Process adalah sebagai berikut :

a. Mendefinisikan masalah serta menentukan solusi yang diinginkan dan kemudian menyusun jaringan dari permasalahan yang dihadapi.

b. Menentukan prioritas elemen dengan membuat perbandingan berpasangan sesuai dengan kriteria yang diberikan, dengan mengelompokkan kriteria dalam komponen yang sama untuk mengetahui suatu tingkat kepentingan terhadap kriteria.

c. Menghitung bobot elemen.

Vektor prioritas $w$ yang disebut eigen vector dihitung dengan rumus :

$$
A . w=\lambda_{\max } w
$$

dengan $A$ adalah matriks perbandingan berpasangan dan $\lambda_{\text {max }}$ adalah eigen vector terbesar dari $A$. Eigen vector merupakan bobot prioritas suatu matriks.

Dalam menganalisis konsistensi dan membuat keputusan, penting untuk mengetahui seberapa baik konsistensi yang ada karena kita tidak menginginkan keputusan berdasarkan pertimbangan dengan konsistensi yang rendah. Consistency Index (CI) dan Consistency Rasio (CR) didefinisikan sebagai :

$$
C I=\frac{\lambda \max -n}{n-1}
$$

dengan CI menyatakan Consistency Index, $\lambda \max$ merupakan nilai rata-rata keseluruhan kriteria dan $n$ adalah jumlah matriks perbandingan kriteria.

$$
C R=\frac{C I}{R I}
$$

dengan CR menyatakan Consistency Rasio dan RI adalah Random Index. Indeks random adalah nilai matriks yang memiliki nilai yang telah ditentukan Saaty untuk mengukur konsistensi dari hasil yang diperoleh. Bila matriks perbandingan berpasangan dengan nilai $C R$ lebih kecil dari 0,10 maka 
ketidakkonsistenan pendapat dari pembuat keputusan masih dapat diterima dan jika lebih dari 0,10 maka pendapat pengambil keputusan tidak bisa diterima dan perlu dilakukan penilaian ulang.

d. Prioritas super matrix.

Prioritas dari sebuah elemen dalam komponen adalah indikator dari prioritas komponen tersebut dalam keseluruhan komponen. Supermatriks merupakan hasil vektor prioritas dari perbandingan berpasangan antar cluster, kriteria, dan subkriteria. Untuk memperoleh nilai super matrix dilakukan dengan cara mengalikan supermatriks tersebut dengan dirinya sendiri sampai beberapa kali. Ketika bobot pada setiap kolom memiliki nilai yang sama, maka super matrix sudah diperoleh.

Diagram alir tahapan penggunaan metode Analytic Network Process (ANP) untuk pembobotan kriteria ditunjukkan pada Gambar 1.

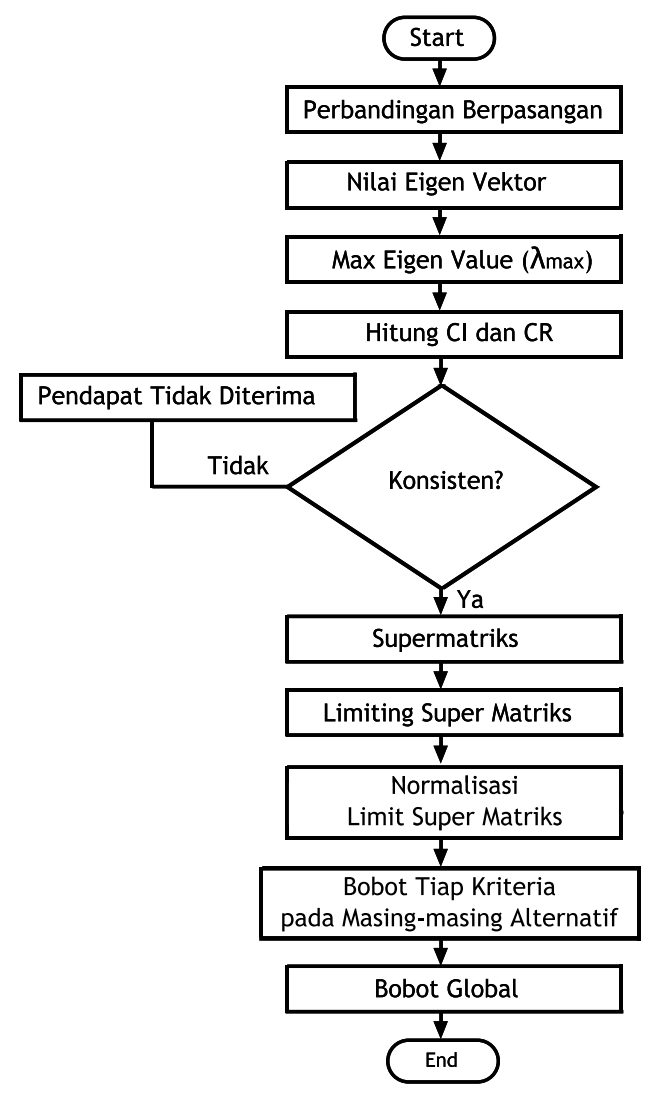

Gambar 1. Diagram Alir Metode ANP

\subsection{Preference Ranking Organization Method For Enrichment Evaluation (PROMETHEE)}

Metode PROMETHEE (Preference Ranking Organization Method for Enrichment Evaluation) adalah metode outranking yang menawarkan cara yang fleksibel dan sederhana kepada pembuat keputusan untuk menganalisis masalah-masalah multi kriteria. Dugaan dari dominasi kriteria yang digunakan dalam PROMETHEE adalah penggunaan nilai dalam hubungan outranking (Brans dan Vinckle, 1986).

Metode PROMETHEE dapat dijelaskan dalam tiga tahapan:

a. Mengumpulkan semua struktur preferensi.

Memaparkan kriteria yang dijadikan untuk mendapatkan pertimbangan dari rentang deviasi dalam penilaian sebuah alternatif dari tiap kriteria yang ada.

b. Mengumpulkan relasi yang dominan.

Relasi outranking dibuat sesuai dengan estimasi dari alternatif dari semua kriteria. Total tingkatan dari preferensi adalah suatu alternatif yang mana mendominasi dari hitungan untuk masing-masing pasangan alternatif yang lain.

c. Analisis keputusan.

Metode PROMETHEE I memberikan sebuah peringkat sebagian dari set a. Informasi akan alternatif yang tidak memiliki tandingan juga telah diberikan. Metode PROMETHEE II akan memberikan peringkat yang komplit dari set $\mathbf{a}$.

Jika a adalah set dari alternatif pilihan yang mungkin terjadi, f1, f2 ..., fk adalah kriteria yang mana telah dievaluasi sebelumnya. Apabila semua kriteria memiliki kriteria yang memiliki tingkat kepentingan yang tidak sama, pembobotannya dapat ditandai dengan w1, w2 ..., wk. Dasar untuk melakukan evaluasi dengan Preference Ranking Organization Method For Enrichment Evaluation disajikan pada Tabel 1.

Tabel 1. Dasar Evaluasi Metode PROMETHEE

\begin{tabular}{|c|c|c|c|c|c|c|}
\hline \multirow[t]{2}{*}{$\mathrm{z}$} & f1(.) & f2(.) & & $\mathrm{fj}()$. & & $\mathrm{fk}()$. \\
\hline & w1 & w2 & $\cdots$ & wj & $\ldots$ & wk \\
\hline \multirow{2}{*}{ a1 } & f1 & $\mathrm{f} 2$ & & $\mathrm{fj}$ & & $\mathrm{fk}$ \\
\hline & (a1) & (a1) & & (a1) & & (a1) \\
\hline \multirow{2}{*}{$\mathrm{a} 2$} & f1 & f2 & & $\mathrm{fj}$ & & $\mathrm{fk}$ \\
\hline & (a2) & (a2) & & (a2) & & (a2) \\
\hline$\cdots$ & $\cdots$ & $\cdots$ & $\ldots$ & $\cdots$ & $\cdots$ & $\ldots$ \\
\hline \multirow{2}{*}{ ai } & f1 & $\mathrm{f} 2$ & & fj & & $\mathrm{fk}$ \\
\hline & (ai) & & $\cdots$ & (ai) & $\cdots$ & (ai) \\
\hline \multirow[b]{2}{*}{ an } & f1 & f2 & & $\mathrm{fj}$ & & $\mathrm{fk}$ \\
\hline & (an) & & $\cdots$ & & $\cdots$ & (an) \\
\hline
\end{tabular}

PROMETHEE I adalah partial ranking di mana nilai terbesar pada leaving flow dan nilai terkecil dari entering flow merupakan alternatif yang terbaik. PROMETHEE I menampilkan partial ranking 
dengan mempertimbangkan interaksi dari dua preorder. Dengan menggunakan metode PROMETHEE I masih menyisakan bentuk incomparible atau dengan kata lain hanya menghasilkan solusi partial ranking (peringkat sebagian). Jika pembuat keputusan menginginkan sebuah solusi komplit maka hendaknya menggunakan PROMETHEE II (complete preorder) yang disajikan dalam bentuk net flow. Melalui complete ranking, informasi bagi pembuat keputusan lebih realistik karena dapat membuat perbandingan terhadap semua alternatif yang muncul.

Untuk memberikan gambaran yang lebih baik terhadap area yang tidak sama maka digunakan fungsi selisih nilai kriteria antar alternatif $H(d)$ di mana hal ini mempunyai hubungan langsung dengan fungsi preferensi $p$. Dalam PROMETHEE disajikan 6 (enam) fungsi preferensi kriteria :

a. Kriteria Biasa (Usual Criterion)

$$
H(d)= \begin{cases}0 & |d|=0 \\ 1 & |d|>0\end{cases}
$$

b. Kriteria Quasi (Quasi Criterion)

$$
H(d)= \begin{cases}0 & |d| \leq q \\ 1 & |d|>q\end{cases}
$$

c. Kriteria Preferensi Linier

$$
H(d)=\left\{\begin{array}{cc}
\frac{|d|}{p} & |d| \leq p \\
1 & |d|>p
\end{array}\right.
$$

d. Kriteria Level

$$
H(d)=\left\{\begin{array}{lr}
0 & |d| \leq q \\
\frac{1}{2} q< & |d| \leq p \\
1 & |d|>p
\end{array}\right.
$$

e. Kriteria Preferensi Linier Area yang Tidak Berbeda

$$
H(d)=\left\{\begin{array}{lr}
0 & |d| \leq q \\
\frac{|d|-q}{p-q} & q<|d| \leq p \\
1 & |d|>p
\end{array}\right.
$$

\section{f. Kriteria Gausian (Gaussian Criterion)}

$$
H(d)=1-\exp \left(-d^{2} / 2 \sigma^{2}\right)
$$

Keterangan :

$H(d)$ : Fungsi selisih kriteria antar alternatif

$d \quad$ : Selisih nilai kriteria $\{d=f(\mathrm{a})-f(\mathrm{~b})\}$

$p \quad:$ Preference dan $q$ : Indifference

Indeks preferensi merupakan intensitas preferensi pembuat keputusan yang menyatakan bahwa alternatif $\boldsymbol{a}$ lebih baik daripada $\boldsymbol{b}$ dengan pertimbangan meliputi seluruh kriteria. Pada indeks preferensi jika semua kriteria memiliki nilai kepentingan yang sama dalam pengambilan keputusan maka semua nilai bobot sama atau sebaliknya. Rumus perhitungan indeks preferensi ditunjukkan pada persamaan di bawah ini :

$$
\wp(a, b)=\sum_{i}^{n} \pi P_{i}(a, b): \forall a, b \in a
$$

Keterangan :

$P_{i}$ : Fungsi preferensi

$\pi:$ Bobot

$\wp(a, b)$ merupakan intensitas preferensi pembuat keputusan yang menyatakan bahwa alternatif $\boldsymbol{a}$ lebih baik dari alternatif $\boldsymbol{b}$ dengan pertimbangan secara simultan dari seluruh kriteria. Hal ini dapat disajikan dengan nilai antara 0 dan 1 , dengan ketentuan sebagai berikut :

a. $(a, b) \approx 0$, menunjukkan preferensi yang lemah untuk alternatif $\boldsymbol{a}$ lebih dari $\boldsymbol{b}$ berdasarkan semua kriteria.

b. $(a, b) \approx 1$, menunjukkan preferensi yang kuat untuk alternatif $\boldsymbol{a}$ lebih dari $\boldsymbol{b}$ berdasarkan semua kriteria.

Indeks preferensi ditentukan berdasarkan nilai outranking pada sejumlah kriteria atau subkriteria dari masing-masing alternatif. Hubungan ini dapat disajikan sebagai bentuk grafik nilai outranking, node-nodenya merupakan alternatif berdasarkan penilaian kriteria tertentu. Perhitungan arah preferensi dipertimbangkan atas nilai indeks leaving flow $\left(\Phi^{+}\right)$, entering flow $\left(\Phi^{-}\right)$, dan net flow $\left(\Phi_{a}\right)$.

Rumus persamaan perhitungan nilai leaving flow ditunjukkan pada persamaan berikut ini :

$$
\Phi^{+}(a)=\frac{1}{\mathrm{n}-1} \sum_{x \in a} \wp(x, a)
$$

Rumus persamaan perhitungan nilai entering flow ditunjukkan pada persamaan di bawah ini :

$$
\Phi^{-}(a)=\frac{1}{n-1} \sum_{x \in a} \wp(x, a)
$$

Perhitungan leaving flow dan entering flow hanya memberikan solusi partial preorder (sebagian), untuk itu harus dilanjutkan perhitungan untuk mendapatkan nilai net flow. Rumus persamaan perhitungan net flow ditunjukkan pada persamaan di bawah ini :

$$
\Phi_{a}=\Phi^{+}(a)-\Phi^{-}(a)
$$

Nilai net flow $\left(\Phi_{a}\right)$ berasal dari perhitungan selisih dari nilai leaving flow $\left(\Phi^{+}\right)$dan entering flow $\left(\Phi^{-}\right)$. Net flow diperoleh dari leaving flow dikurangi dengan entering flow. Jadi, jika semakin besar nilai leaving flow dan semakin kecil nilai entering flow, maka alternatif akan memiliki nilai net flow yang besar. 


\section{Metode}

\subsection{Kerangka Kerja Sistem Pemilihan Supplier}

Penelitian pemilihan supplier dengan menggunakan kombinasi ANP-PROMETHEE dimulai dari input: data pendapat responden dari pihak perusahaan berupa kuesioner untuk pembobotan kriteria. Data kemudian diproses dengan perhitungan ANP yaitu input perbandingan, matrik perbandingan, dan normalisasi matrik perbandingan, unweighted supermatrix, weighted supermatrix, limiting supermatrix, dan normalisasi limiting supermatrix. Setelah bobot kriteria didapatkan, proses dilanjutkan pada perhitungan PROMETHEE yaitu dimulai dari input: data nilai asli kriteria yang kemudian dilakukan reduksi data dengan cara mengubah data tersebut menjadi sebuah urutan sehingga data menjadi seimbang. Data kemudian dikalikan dengan bobot dari perhitungan ANP dan dilanjutkan ke tahap selanjutnya yaitu penentuan tipe fungsi preferensi, perhitungan nilai preferensi, indeks preferensi, leaving flow, entering flow, dan net flow. Output yang dihasilkan berupa ranking alternatif (supplier plat 6 feed $14 \mathrm{~mm}$ ). Konsep kerangka kerja sistem ditunjukkan pada Gambar 2.

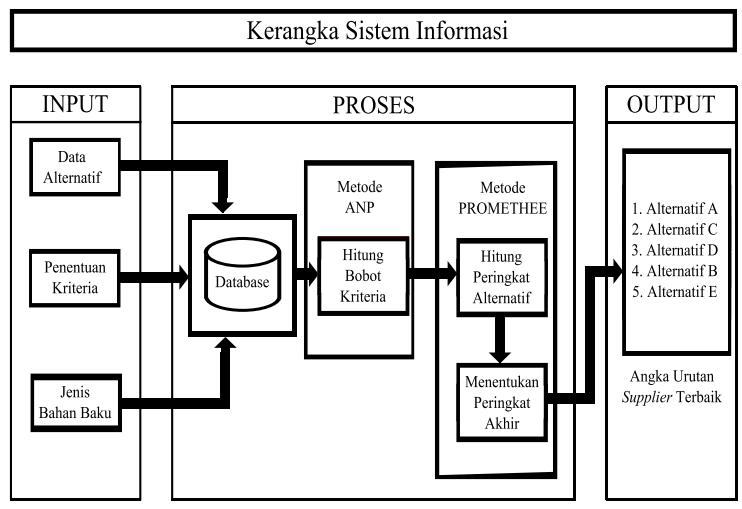

Gambar 2. Kerangka kerja sistem pemilihan supplier

\subsection{Data dan Variable Penelitian}

Data diambil dari perusahaan PT. Lamongan Marine Industry dan beberapa data pendukung. Dari data tersebut kemudian diambil 4 kriteria yang kemudian di-breakdown menjadi 14 sub kriteria. Adapun kriteria dan sub kriteria yang menjadi acuan penilaian terhadap supplier adalah sebagai berikut :

- Kriteria :

- Harga (A)

- Pengiriman (B)

- Kualitas (C)

- Infrastruktur (D)
- Sub kriteria :

- Harga Penawaran (A1)

- Potongan Harga / Diskon (A2)

- Ketepatan Pengiriman (B1)

- Biaya Kirim (B2)

- Packing (B3)

- Kelengkapan Dokumen (C1)

- Kualitas Produk (C2)

- Kemampuan memberi Kualitas yang Konsisten (C3)

- Jarak Antar Lokasi (D1)

- Peranan Manajemen (D2)

- Teknologi Informasi (D3)

- Sistem Penghargaan (D4)

- Struktur Organisasi (D5)

- Kerjasama (D6)

Pada metode ANP, pembentukan feedback network dilakukan untuk melihat besar pengaruh antar kriteria. Jumlah anak panah pada gambar feedback network ini melambangkan jumlah mempengaruhi dan dipengaruhi pada setiap sub kriteria. Semakin banyak mempengaruhi artinya dianggap semakin penting. Bentuk feedback network ditunjukkan pada Gambar 3.

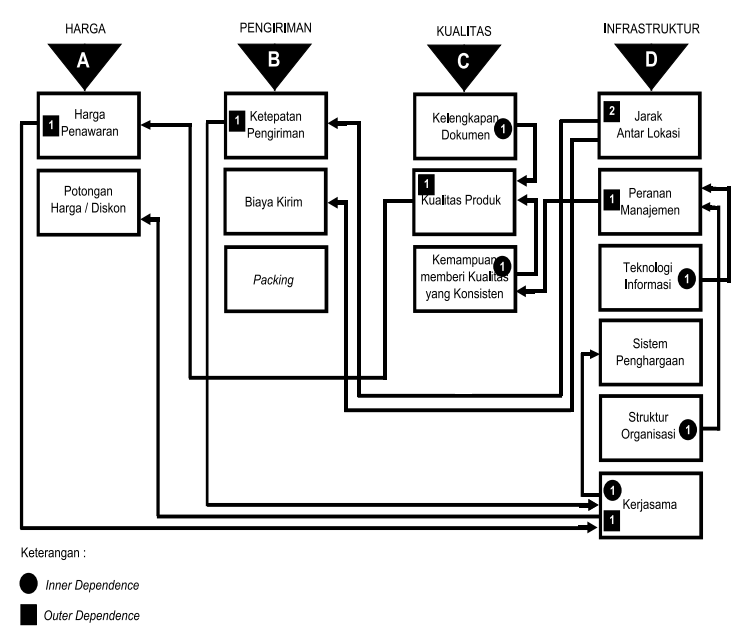

Gambar 3. Feedback Netwok

Dari kriteria serta pertimbangan berdasarkan skema feedback network tersebut lalu diproses dengan kombinasi metode ANP-PROMETHEE dimulai dari penentuan alternatif, penentuan kriteria, hingga peringkatan alternatif.

Diagram alir pada kombinasi metode ANPPROMETHEE ditunjukkan pada Gambar 4. 


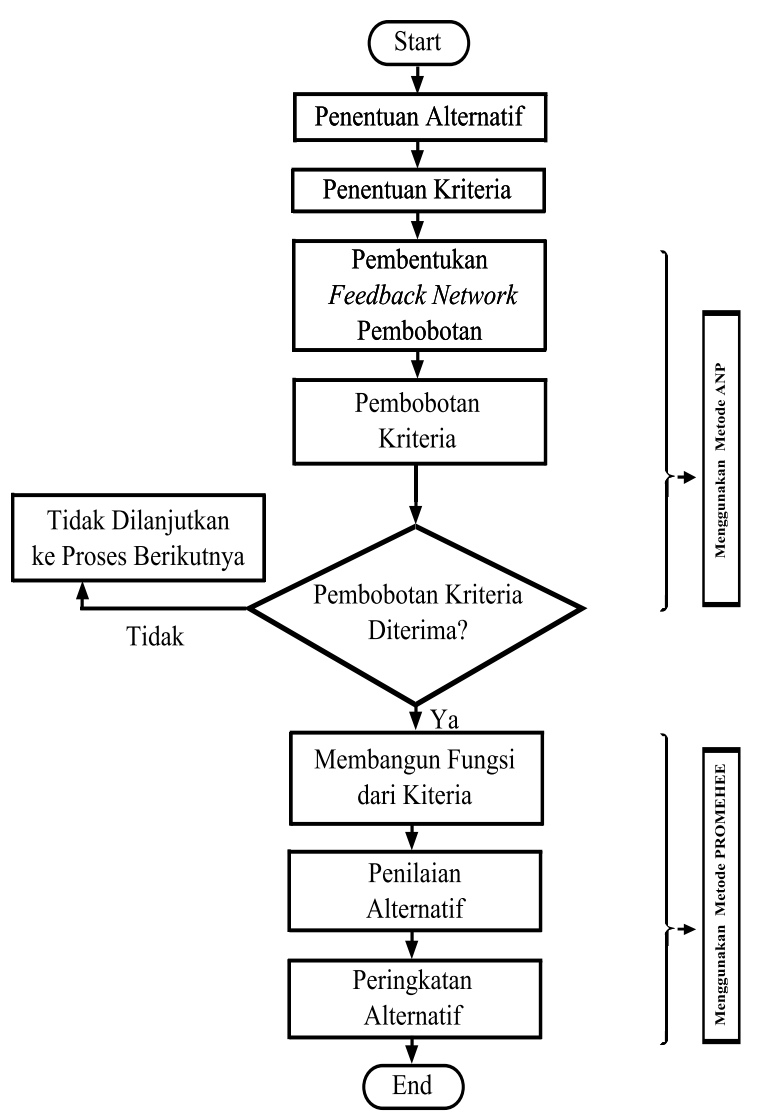

Gambar 4. Diagram Alir Metode ANP-ROMETHEE

Nilai input pada PROMETHEE yang akan dikalikan dengan bobot hasil dari perhitungan ANP merupakan nilai hasil reduksi data dari nilai asli sub kriteria pada setiap alternatif atau supplier. Berikut ini merupakan nilai asli (sebelum reduksi data) yang ada pada semua supplier (SP) yaitu MG, ATT, ESA, YSA, INT, GC, SUT, dan BIZ (Tabel 2, 3 dan 4).

Tabel 2. Nilai Sub Kriteria

\begin{tabular}{cccc}
\hline SP & A1 & A2 & B1 \\
\hline MG & Rp 8.510.980 & Rp 159.586 & 8 \\
ATT & Rp 8.582.754 & Rp 95.178 & 9 \\
ESA & Rp 8.700.000 & Rp 65.250 & 4 \\
YSA & Rp 8.582.549 & Rp 75.839 & 1 \\
INT & Rp 8.577.365 & Rp 128.964 & 16 \\
GC & Rp 8.581.875 & Rp 98.164 & 1 \\
SUT & Rp 8.659.615 & Rp 93.288 & 5 \\
BIZ & Rp 8.580.394 & Rp 152.408 & 11 \\
\hline
\end{tabular}

Tabel 3. Nilai Sub Kriteria (lanjutan 1)

\begin{tabular}{ccccc}
\hline SP & B2 & B3 & C1 & C2 \\
\hline MG & Rp 3.250.000 & 55,69 & 62,50 & 45,63 \\
ATT & Rp 2.500.000 & 58,57 & 10,00 & 42,14 \\
ESA & Rp 2.750.000 & 10,00 & 56,67 & 13,33 \\
YSA & Rp 3.250.000 & 30,00 & 43,33 & 31,67 \\
INT & Rp 4.750.000 & 65,56 & 50,00 & 36,67 \\
GC & Rp 2.500.000 & 90,00 & 23,33 & 20,00 \\
SUT & Rp 2.750.000 & 65,00 & 90,00 & 50,00 \\
BIZ & Rp 3.250.000 & 65,38 & 77,69 & 40,77 \\
\hline
\end{tabular}

Tabel 4. Nilai Sub Kriteria (lanjutan 2)

\begin{tabular}{cccccccc}
\hline SP & C3 & D1 & D2 & D3 & D4 & D5 & D6 \\
\hline MG & $79 \%$ & 200 & 10 & 50 & 50 & 50 & 3 \\
ATT & $60 \%$ & 125 & 10 & 10 & 10 & 50 & 5 \\
ESA & $67 \%$ & 150 & 50 & 50 & 50 & 90 & 5 \\
YSA & $63 \%$ & 200 & 50 & 90 & 10 & 90 & 5 \\
INT & $83 \%$ & 350 & 10 & 10 & 10 & 50 & 7 \\
GC & $73 \%$ & 200 & 90 & 50 & 50 & 90 & 8 \\
SUT & $77 \%$ & 150 & 90 & 90 & 90 & 90 & 8 \\
BIZ & $76 \%$ & 125 & 50 & 10 & 90 & 90 & 9 \\
\hline
\end{tabular}

Pada penelitian ini, terdapat 3 jenis tipe preferensi yang dipilih dalam perhitungan PROMETHEE.

- Tipe preferensi I dipilih untuk sub kriteria B1, B2, B3, C3, D1, D2, D3, D4, D5, dan D6. Tipe ini dipilih karena nilai-nilai yang ada pada sub kriteria tersebut cenderung bersifat stabil dan tidak mudah berubah. Sehingga perbedaan sekecil apapun tidak diberikan toleransi ambang batas atau threshold.

- Tipe preferensi II dipilih untuk sub kriteria C1 dan C2. Tipe ini dipilih karena nilai-nilai yang ada pada sub kriteria tersebut bersifat agak fleksibel dan sedikit mudah berubah karena merepresentasikan sebuah kualitas atas bahan/barang. Sehingga perbedaan yang ada masih memungkinkan untuk ditoleransi dengan batas tertentu atau threshold tertentu (q).

- Tipe preferensi III dipilih untuk sub kriteria A1 dan A2. Tipe ini dipilih karena nilai-nilai yang ada pada sub kriteria tersebut bersifat sangat fleksibel dan sangat mudah berubah karena merepresentasikan sebuah kuantitas atau nominal atas barang. Sehingga perbedaan yang ada masih memungkinkan untuk ditoleransi dengan batas tertentu atau threshold tertentu (p).

Kaidah min/max dipilih berdasarkan sifat sub kriteria. Jika semakin besar nilai yang ada pada sub kriteria bersifat semakin menguntungkan, maka yang dipilih adalah kaidah max. Sedangkan jika semakin besar nilai yang ada pada sub kriteria bersifat semakin merugikan, maka yang dipilih adalah kaidah $\min$.

\section{Hasil dan Pembahasan}

\subsection{Hasil Ranking Alternatif}

Hasil ranking alternatif didapat dari hasil perhitungan net flow setiap responden/pakar (P). Hasil perhitungan net flow semua pakar yaitu P1, P2, P3, P4, P5, dan P6 terlihat pada Tabel 5 dan 6. 
Tabel 5. Hasil Perhitungan Net Flow Setiap Pakar

\begin{tabular}{cccc}
\hline SP & P1 & P2 & P3 \\
\hline MG & $-0,015$ & $-0,012$ & $-0,012$ \\
ATT & $-0,035$ & $-0,035$ & $-0,038$ \\
ESA & $-0,018$ & $-0,021$ & $-0,02$ \\
YSA & $-0,004$ & $-0,005$ & $-0,005$ \\
INT & $-0,011$ & $-0,009$ & $-0,009$ \\
GC & 0,029 & 0,026 & 0,026 \\
SUT & 0,027 & 0,029 & 0,029 \\
BIZ & 0,026 & 0,028 & 0,026 \\
\hline
\end{tabular}

Tabel 6. Hasil Perhitungan Net Flow Setiap Pakar (lanjutan)

\begin{tabular}{cccc}
\hline SP & P4 & P5 & P6 \\
\hline MG & $-0,012$ & $-0,013$ & $-0,013$ \\
ATT & $-0,036$ & $-0,036$ & $-0,036$ \\
ESA & $-0,02$ & $-0,019$ & $-0,02$ \\
YSA & $-0,006$ & $-0,005$ & $-0,005$ \\
INT & $-0,007$ & $-0,009$ & $-0,027$ \\
GC & 0,026 & 0,028 & 0,027 \\
SUT & 0,028 & 0,027 & 0,027 \\
BIZ & 0,028 & 0,027 & 0,027 \\
\hline
\end{tabular}

Pada kasus penelitian ini, terdapat pakar (responden) ke-3 (P3) namun pendapatnya dianggap tidak konsisten karena hasil perhitungan Consistensy Rasio (CR) di atas treshold atau ambang batas Consistensy Rasio (CR) yaitu 0,1. Oleh karena itu perhitungan untuk pakar ke-3 (R3) tidak dapat dilanjutkan ke tahap perhitungan berikutnya dan pendapatnya diabaikan karena pendapatnya dianggap gugur. Hasil perhitungan net flow semua pakar dengan nilai Consistensy Rasio (CR) di bawah atau sama dengan 0,1 (pendapatnya dianggap konsisten) kemudian direkapitulasi menjadi satu net flow di mana output hasil dari rekapitulasi ini merupakan hasil akhir proses ranking alternatif dan sebagai dasar dalam penentuan supplier plat 6 feed 14 milimeter terbaik bagi perusahaan. Supplier dengan nilai net flow yang terbesar dari rekapitulasi ini dianggap sebagai supplier terbaik bagi perusahaan. Hasil perhitungan net flow semua pakar (responden) ditunjukkan pada Tabel 7.

Dari data hasil perhitungan net flow semua responden tersebut (Tabel 7) maka didapatkan bahwa supplier terbaik bagi perusahaan untuk bahan plat 6 feed dengan ketebalan 14 milimeter adalah SUT dengan nilai net flow 0,0276 .
Tabel 7. Hasil Perhitungan Net Flow Semua Pakar

\begin{tabular}{cccc}
\hline SP & $\begin{array}{c}\text { Net Flow } \\
\text { (Sum) }\end{array}$ & $\begin{array}{c}\text { Net Flow } \\
\text { (Avg) }\end{array}$ & Rank \\
\hline MG & $-0,065$ & $-0,013$ & 6 \\
ATT & $-0,178$ & $-0,0356$ & 8 \\
ESA & $-0,098$ & $-0,0196$ & 7 \\
YSA & $-0,025$ & $-0,005$ & 4 \\
INT & -0.063 & $-0,0126$ & 5 \\
GC & 0,136 & 0,0272 & 2 \\
SUT & 0,138 & 0,0276 & 1 \\
BIZ & 0,136 & 0,0272 & 2 \\
\hline
\end{tabular}

\subsection{Hasil Pengujian Sistem Pemilihan Supplier}

Berdasarkan sistem yang telah dikembangkan, kemudian dilakukan proses validasi untuk menunjukkan bahwa sistem yang dibuat sesuai dengan kenyataan yang sebenarnya. Proses validasi dilakukan dengan cara membandingkan hasil perhitungan secara manual dengan hasil perhitungan sistem. Proses perhitungan dapat dinyatakan valid jika hasil perhitungan yang dilakukan secara manual sama dengan hasil proses perhitungan yang dilakukan oleh sistem. Dengan menggunakan masukan yang sama, dari hasil perhitungan manual dan perhitungan sistem menghasilkan keluaran yang sama. Hasil validasi manual dan hasil validasi sistem ditunjukkan pada Tabel 8.

Tabel 8. Hasil Validasi Manual dan Hasil Validasi Sistem

\begin{tabular}{cccc}
\hline SP & Net Flow & Rank Manual & Rank Sistem \\
\hline MG & $-0,013$ & 6 & 6 \\
ATT & $-0,0356$ & 8 & 8 \\
ESA & $-0,0196$ & 7 & 7 \\
YSA & $-0,005$ & 4 & 4 \\
INT & $-0,0126$ & 5 & 5 \\
GC & 0,0272 & 2 & 2 \\
SUT & 0,0276 & 1 & 1 \\
BIZ & 0,0272 & 2 & 2 \\
\hline
\end{tabular}

\subsection{Evaluasi ANP-PROMETHEE pada Sistem} Pemilihan Supplier

Pada penelitian ini, evaluasi kombinasi metode ANP-PROMETHEE dilakukan untuk mengetahui tingkat signifikansi kecenderungan dominasi antara masing-masing dua metode yaitu ANP dan PROMETHEE ketika dikombinasikan pada satu pemecahan permasalahan pemilihan supplier dalam mempengaruhi atau menentukan hasil akhir ranking alternatif. Telah dilakukan beberapa kali percobaan (test) dengan cara memasukkan atau mengganti nilai secara acak yang telah dilakukan yaitu pada Test 1 , Test 2, Test 3, dan Test 4. 
Hasil ranking dari percobaan tersebut kemudian dibandingkan dengan hasil ranking dari salah satu pakar yang dalam analisis ini yang dijadikan pembanding adalah pakar 1 (P1). Dengan melihat hasil perbandingan tersebut maka akan terlihat perbedaan hasil yang merupakan representasi tingkat signifikansi pengaruh masing-masing metode (ANP dan PROMETHEE) terhadap hasil akhir.

Percobaan pertama (Test 1) merupakan test yang dilakukan dengan cara memasukkan nilai secara acak pada ANP dengan nilai-nilai masukan yang interval angkanya tidak terlalu besar sehingga hasil perhitungan Consistensy Rasio (CR) masih jauh dari angka 0,1 (tidak mendekati batas ketidak konsistenan) di mana pada kasus ini Consistensy Rasio (CR)-nya adalah 0,0629. Dari test ini didapatkan hasil bahwa perubahan nilai masukan pada ANP mempunyai pengaruh yang tidak terlalu signifikan. Nilai acak dari percobaan tersebut hanya mampu menghasilkan perubahan nominal angka hasil perhitungan ranking tetapi tidak menghasilkan perubahan urutan ranking.

Percobaan kedua (Test 2) merupakan test yang dilakukan dengan cara memasukkan nilai secara acak pada ANP dengan nilai-nilai masukan yang interval angkanya sangat besar sehingga hasil perhitungan Consistensy Rasio mendekati angka 0,1 (mendekati batas ketidakkonsistenan) di mana pada kasus ini Consistensy Rasio (CR)-nya adalah 0,0993. Dari test ini didapatkan hasil bahwa perubahan nilai masukan pada ANP mempunyai pengaruh yang signifikan. Nilai acak dari percobaan tersebut mampu menghasilkan perubahan nominal angka hasil perhitungan ranking maupun perubahan urutan ranking.

Percobaan ketiga (Test 3) merupakan test yang dilakukan dengan cara memasukkan nilai secara acak pada PROMETHEE dengan melakukan perubahan nilai-nilai masukan hanya pada satu kolom. Dari test ini didapatkan hasil bahwa perubahan nilai masukan pada PROMETHEE mempunyai pengaruh yang signifikan meskipun perubahan nilai-nilai masukan hanya dilakukan pada satu kolom. Nilai acak dari percobaan tersebut mampu menghasilkan perubahan nominal angka hasil perhitungan ranking maupun perubahan urutan ranking.

Percobaan keempat (Test 4) merupakan test yang dilakukan dengan cara memasukkan nilai secara acak pada PROMETHEE dengan melakukan perubahan nilai-nilai masukan lebih dari satu kolom. Dari test ini didapatkan hasil bahwa perubahan nilai masukan pada PROMETHEE mempunyai pengaruh yang signifikan. Nilai acak dari percobaan tersebut mampu menghasilkan perubahan nominal angka hasil perhitungan ranking maupun perubahan urutan ranking.

Hasil rekapitulasi perhitungan net flow dari semua test yang dilakukan ditunjukkan pada Tabel 9.
Tabel 9. Rekapitulasi Net Flow Semua Test

\begin{tabular}{cccccc}
\hline \multirow{2}{*}{ SP } & $\begin{array}{c}\text { Rank } \\
\text { P1 }\end{array}$ & $\begin{array}{c}\text { Rank } \\
\text { Test 1 }\end{array}$ & $\begin{array}{c}\text { Rank } \\
\text { Test 2 }\end{array}$ & $\begin{array}{c}\text { Rank } \\
\text { Test 3 }\end{array}$ & $\begin{array}{c}\text { Rank } \\
\text { Test 4 }\end{array}$ \\
\hline MG & 6 & 6 & 6 & 7 & 6 \\
ATT & 8 & 8 & 8 & 8 & 8 \\
ESA & 7 & 7 & 7 & 6 & 4 \\
YSA & 4 & 4 & 4 & 4 & 5 \\
INT & 5 & 5 & 4 & 5 & 6 \\
GC & 1 & 1 & 2 & 2 & 3 \\
SUT & 2 & 2 & 2 & 1 & 2 \\
BIZ & 3 & 3 & 1 & 3 & 1 \\
\hline
\end{tabular}

\section{Kesimpulan}

Berdasarkan hasil penelitian yang dilakukan, dapat diambil beberapa kesimpulan diantaranya adalah bahwa kombinasi metode ANPPROMETHEE mampu bekerja atau berfungsi dengan baik saat diimplementasikan dalam sistem pendukung keputusan untuk pemilihan supplier. Metode Analytical Network Process (ANP) mampu menangani permasalahan dari sisi kompleksitas banyaknya alternatif (supplier) dan variabel (sub kriteria) agar tetap obyektif dalam melakukan penilaian, sedangkan metode Preference Ranking Organization Method For Enrichment Evaluation (PROMETHEE) mampu menangani permasalahan dari sisi kompleksitas atribut dari setiap variabel agar tepat dalam menentukan tingkat kepentingan setiap atribut yang telah ditentukan. Dengan kata lain, metode Analytical Network Process (ANP) lebih cenderung mampu menangani permasalahan dalam hal Multiple Objective Decision Making (MODM), sedangkan metode Preference Ranking Organization Method For Enrichment Evaluation (PROMETHEE) lebih cenderung mampu menangani permasalahan dalam hal Multi Attribute Decision Making (MADM) di mana dua hal ini (MODM dan MADM) merupakan bagian inti dari Multi Criteria Decision Making (MCDM). Kesimpulan penting lainnya yang didapat dari penelitian ini adalah bahwa nilai masukan yang ada pada ANP mempunyai pengaruh yang kurang signifikan pada hasil akhir ranking ketika hasil perhitungan Consistency Rasio (CR) berada di angka jauh dari threshold CR, dalam penelitian ini hasil perhitungan Consistency Rasio (CR) yang diujicobakan adalah pada angka 0,0629 dan terbukti tidak mampu mengubah urutan akhir ranking alternatif. Nilai masukan yang ada pada ANP mempunyai pengaruh yang signifikan pada hasil akhir ranking ketika hasil perhitungan Consistency Rasio (CR) pendapat pakar mendekati angka threshold CR $(0,1)$, dalam penelitian ini hasil perhitungan Consistency Rasio (CR) yang diujicobakan adalah pada angka 0,0993 dan terbukti mampu mengubah hasil akhir urutan ranking alternatif, sedangkan nilai masukan yang 
ada pada PROMETHEE mempunyai pengaruh yang signifikan dan mampu mengubah urutan akhir ranking alternatif meskipun hanya dilakukan perubahan pada sebagian kecil angka masukan. Artinya nilai-nilai yang ada PROMETHEE mempunyai pengaruh yang lebih signifikan dibandingkan nilai-nilai yang dihasilkan dari pembobotan ANP dalam menentukan hasil akhir peringkat supplier. Implementasi metode ANPPROMETHEE terbukti mampu menghasilkan keluaran alternatif (supplier) terbaik secara lebih rasional dibandingkan dengan penilaian secara manual dan subyektif. Dengan demikian, dalam penelitian ini percobaan pertama (Test 1) adalah percobaan yang hasilnya paling mendekati pendapat pakar yaitu percobaan yang melibatkan angka masukan ANP dengan perubahan (interval) angka yang kecil, sedangkan percobaan yang hasilnya paling menjauhi pendapat pakar adalah percobaan keempat (Test 4) yaitu percoaan dengan melibatkan angka masukan PROMETHEE dengan perubahan nilai masukan lebih dari satu kolom. Berdasarkan hal tersebut, maka sistem yang dirancang dapat dijadikan sebagai acuan untuk melakukan pemilihan supplier terbaik.

\section{Daftar Pustaka}

Brans, J.P. and Vinckle, P.H., 1986. A Preference Ranking Organisation Method: (The PROMETHEE Method for Multiple Criteria Decision-Making, Managemenet Science (31), 647-656.

Bruno, G., Esposito, E., Genovese, A. and Passaro, R., 2012. AHP-based approaches for supplier evaluation: Problems and perspectives, Journal of Purchasing \&Supply Management (18), 159-172.

Dobos, I., dan Vörösmarty, G., 2014. Green supplier selection and evaluation using DEA-type composit indicators, Int. J. Production Economics (157), 273-278.
Govindan, K., Rajendran, S., Sarkis, J. and Murugesan, P., 2015. Multi criteria decision making approaches for green supplier evaluation and selection: a literature review, Journal of Cleaner Production (98), 66-83.

Hu, Y.C. and Chen, C.J., 2011. A PROMETHEEbased classification method using concordance and discordance relations and its application to bankruptcy prediction. Information Sciences (181), 4959-4968.

Kilic, H.S., Zaim, S. and Delen, D., 2015. Selecting "The Best" ERP system for SMEs using a combination of ANP and PROMETHEE methods, Expert Systems with Applications (42), 2343-2352.

Lami, I.M. and Abastante F., 2014. Decision making for urban solid waste treatment in the context of territorial conflict: Can the Analytic Network Process help? In: LAND USE POLICY (41), 1120.

Peng, A.H. and Xiao, X.M., 2013. Material selection using PROMETHEE combined with analytic network process under hybrid environment, Materials and Design (47), 643-652.

Rafiei, H. and Rabbani, M., 2014. Hybrid MTS/MTO order partitioning framework based upon fuzzy analytic network process, Applied Soft Computing (19), 312-321.

Saaty, T.L., 1996. Decision Making with Dependence and Feedback The Analytic Network Process, RWS Publications, Pittsburgh.

Saaty, T.L., 1999. Fundamentals of the Analytic Network Process, ISAHP, Kobe, Japan.

Shiue, Y.C. and Lin, C.Y., 2012. Applying analytic network process to evaluate the optimal recycling strategy in upstream of solar energy industry, Energy and Buildings (54), 266- 277.

Vinodh, S. and Girubha R.J., 2012. PROMETHEE based sustainable concept selection. Applied Mathematical Modelling (36), 5301-5308. 